\title{
REGIMMENES MIMÉTICOS EN PUGNA EN ALTAZOR DE VICENTE HUIDOBRO
}

\author{
CONFLICTING MIMETIC REGIMES IN ALTAZOR \\ BY VICENTE HUIDOBRO
}

\section{ILINCA ILIAN*}

\section{RESUMEN}

El artículo pretende poner de manifiesto el doble régimen del "realismo" utilizado en Altazor de Vicente Huidobro, valiéndonos de los trabajos de François Rastier, y observar como en su obra maestra el poeta chileno está forzado a superar totalmente su poética creacionista basada en una confusión ontológica ruinosa, verbigracia la ilusión de emular poéticamente la magia primitiva. Rastier muestra que, entre las dos tradiciones de la literatura occidental, por un lado el realismo empírico, basado en la representación de lo sensible e ilustrado especialmente por la novela clásica, y por otro lado el realismo transcendental, asociado con la expresión lírica, el surrealismo ha elegido la vía de la antinomia, que destruye las dos formas clásicas miméticas, tanto las empíricas como las transcendentales. En cambio, en el caso del creacionismo, creemos que podemos hablar de la co-presencia conflictiva a lo largo del poema de los dos tipos de realismos, empírico y transcendental. La solución del poeta consiste en imaginar una palabra que no se reduzca a una imagen mental y tampoco salga por completo de los límites de la representación.

Palabras clave: Vicente Huidobro, François Rastier, mimesis, representabilidad, poética creacionista.

\section{ABSTRACT}

This paper focuses on the double pattern of "realism" present in Vicente Huidobro's Altazor by making use of François Rastier's work in order to highlight how in his masterpiece the Chilean poet feels forced to overcome his creationist aesthetics based on

* Profesora titular Universidad de Oeste de Timisoara, Rumania. Correo electrónico: ilincasn @gmail.com 
a ruinous ontological confusion, such as the illusion of poetically emulating primitive magic. Rastier shows that, unlike the two traditions of western literature, i.e. empirical realism, based on the representation of sensitivity and illustrated by the classical novel, and transcendental realism, associated with lyrical expression, surrealism chooses antinomy, which destroys both traditional mimetic forms. In the case of creationism, however, we believe we can talk about the conflicting co-presence of the two types of realism, empirical and transcendental, throughout the poem. The poet's solution is to imagine a word that neither narrows down to a mere mental image nor goes beyond the limits of representation.

Keywords: Vicente Huidobro, François Rastier, mimesis, representability, the poetics of creationism.

Recibido: 09.10.17. Aceptado: 12.12.17.

PESAR DE LOS ATAQUeS a los que lo sometió Guillermo de la Torre, que
se esforzó por minimizar el rol desempeñado por Huidobro en la
iniciación del ultraísmo (Robles, 1971, p. 96), el autor de Altazor produjo una conmoción innegable en los círculos vanguardistas madrileños. Rafael Cansinos-Assens declaró en 1927 que "el acontecimiento supremo del año literario que ahora acaba, lo constituye el tránsito por esta corte del joven poeta chileno Vicente Huidobro" (p. 100) y de hecho el propio De la Torre, en una carta personal dirigida al poeta, hablaba del "pasmo" que produjo su poesía en Madrid y del efecto que tuvo, esto es la creación del primer manifiesto ultra: "Cansinos-Assens ha aprovechado el pasmo por usted suscitado para promover un manifiesto sintético firmado por algunos de nosotros, una nueva escuela postnovecentista a la que denominaremos ultraísmo" (p. 99). La fascinación producida por Huidobro se debía evidentemente a una desmesura que cuadraba con las expectativas de los jóvenes literatos reunidos en Madrid, porque sus propuestas enunciaban con grandilocuencia la idea de origen romántico, que se volvió central en la vanguardia, relacionada con la necesidad de desalojar el concepto de mimesis para promover, al menos de forma lúdica y compensatoria, el concepto de poiesis. Leída hoy, "Arte poética" de 1916 de Huidobro parece un prontuario del vanguardismo en el sentido más amplio: se mencionan la calidad demiúrgica del poeta ("El poeta es un pequeño dios"), la preminencia de lo cerebral frente a las efusiones sentimentales ("El vigor verdadero reside en el cerebro"), la obligación de construir mundos nuevos ("Inventa mundos nuevos y cuida tu palabra"). Destaca en esta serie la negación de seguir celebrando lo fenoménico, ilustrada por el antiguo tópico del canto 
a la rosa y expresada en la formulación radical que suele figurar como lema del creacionismo: "Por qué cantáis la rosa, ¡oh Poetas! / Hacedla florecer en el poema"'.

En la base de estas proclamas ruidosas está la falsa analogía que une dos territorios de grados ontológicos diferentes, esto es el mundo empírico y el mundo ficticio suscitado por el poema, cuya relación desencadenó no pocos malentendidos. Las teorías sobre los universos ficticios se acumularon desde los años ochenta, gracias a los trabajos de Thomas Pavel, Lubomir Dolezel, Marie-Laure Ryan, etc., que se reivindican de los trabajos de filosofía analítica iniciados principalmente por Nelson Goodman. Por su parte, François Rastier ha señalado en un artículo de 1992 que las teorías de la referencia ficcional no hacen sino mantener incólume el realismo filosófico de la referencia: "[L]e détour par les mondes posibles permet ainsi de préserver le 'contenu de vérite' du texte et ne pas renoncer au réalisme philosophique de la réference. Ainsi, les théories de la réference fictionnelle entendent-elles préserver le réalisme traditionnel, quitte à le sophistiquer quelque peu" [El desvío por los mundos posibles permite así preservar el 'contenido de verdad' del texto y no renunciar al realismo filosófico de la referencia. Así, las teorías de la referencia ficticia pretenden preservar el realismo tradicional, si bien lo sofistican un poco] (Rastier, 1992a, p. 86). Por eso, en lo que lo concierne, Rastier aboga por el comentario de las obras en tanto obras y no mundos. Sin negar que el texto desencadena impresiones referenciales hechas de imágenes mentales, el filólogo francés propone una hermenéutica interpretativa para la cual la palabra no se define en relación con estados de cosas o con estados mentales, sino que adquiere sentido a través de sus contextos, según el principio de que lo global (el texto) determina lo local (los signos). En vez de analizar las relaciones entre el mundo primario, consensual y los mundos ficticios, vale más, según Rastier, reparar en los regímenes miméticos a los que se subordina el texto, en función del parangón privilegiado: el mundo físico para el realismo empírico o el mundo eidético de las representaciones mentales para el realismo transcendental.

Ahora bien, cualquiera que fuera la concepción sobre la ontología de los textos, es innegable que la descripción de los universos ficticios en términos de mundos es totalmente distinta de la evaluación del mundo empírico como apto de ser transformado por arte de magia poética. La desmesura de las ambiciones creacionistas permite la postulación de una equivalencia sin

\footnotetext{
${ }^{1}$ Todas las citas de los poemas huidobrianos proceden de la edición de René de Costa, 1981.
}

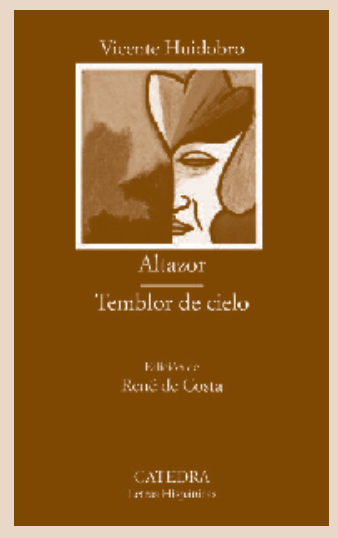


resto entre lo empírico y lo eidético, puesto que Huidobro declara que sus poemas son objetos del mundo y al mismo tiempo son capaces de instaurar una nueva realidad, según explica en 1925 en relación con un poema suyo: "Es un poema en el que cada parte constitutiva, y todo el conjunto, muestra un hecho nuevo, independiente del mundo externo, desligado de cualquiera otra realidad que no sea la propia, pues toma su puesto en el mundo como un fenómeno singular, aparte y distinto de los demás fenómenos" (Huidobro, 1976, p. 733). En "Arte poética" de 1916 equipara la capacidad ontogónica del poeta con la magia misma. Así como el mago primitivo no canta la lluvia, sino que la suscita por un conjuro, de la misma forma procede el poeta con la rosa vista como sinécdoque del universo poético.

Esta concepción sobre la poesía se mantiene en Altazor, cuya elaboración, como demuestra René de Costa, empezó por los años 1919 (Huidobro, 1981, p. 20). La voz poética que protagoniza el poema aparece allí bajo la triple hipóstasis de hombre, poeta y mago. Los siete cantos del poema crean un dispositivo textual regido por el gusto por la disparidad, lo heterogéneo y lo inconexo, pero su aspiración declarada es construir un mundo poético fuera de la temporalidad y la muerte, un mundo que por efecto de magia suplante una realidad empírica insatisfactoria. Tampoco sorprende, entonces, que el resultado de esta desmesurada empresa, que consiste en el empalme de dos órdenes ontológicos distintos, se revele ser en última instancia un estrepitoso fracaso. Aullón de Haro lo declara el propio "fracaso de la Vanguardia" (Aullón de Haro, 1988, p. 58) y Guillermo Sucre puntualiza que Altazor "no [es un poema] sobre el fracaso sino del fracaso; no un comentario alrededor del fracaso sino su presencia misma" (Sucre, 1985, p. 122). Con todo eso, la lenta caída del lenguaje en el territorio preverbal representa un fracaso sólo si se siguen las pautas del realismo empírico, esto es, cuando se lee el poema como una "narración" de la aventura protagonizada por una figura tríadica que crea, en vez del cosmos deseado, un caos que arrastra con él al hombre, al poeta y junto con ellos al mago que pretendía transponer el nuevo mundo en la realidad empírica. En cambio, si consideramos que el poema se inscribe en un realismo transcendente y busca precisamente la salida del mundo empírico dominado por la dualidad y por la muerte, entonces él se lee, según Ávila Rubio, como una "experiencia del triunfo", porque logra llegar a la meta mencionada por el propio poeta chileno en una conferencia de 1921 dada en el Ateneo de Madrid, esto es "el lindero final, [donde] el encadenamiento habitual de los fenómenos rompe su lógica, y al otro lado, en donde empiezan las tierras del poeta, la cadena se rehace en una lógica nueva" (Huidobro, 1976, p. 716). 
Evidentemente, se podría objetar que esta solución poco tiene que ver con la petición radical expresada en el primer canto de Altazor "Quiero la eternidad como una paloma entre mis manos", pero esta contradicción condice con la alternancia de regímenes miméticos en que se desarrolla la aventura poética huidobriana.

El tipo de realismo que rige la lectura del poema es importante porque, así como ha mostrado François Rastier en un texto de 1998, la propia identificación de los tropos depende de ella, ya que lejos de poder reconocerse de por sí, como un adjetivo o un pronombre, los tropos son "une contrainte sur le parcours interprétatif" [una coacción en el recorrido interpretativo] y "en fonction de la stratégie interprétative, on pourra décrire une métaphore comme une conflation ou une bifurcation entre isotopies, selon que sont mis en saillance les traits spécifiques communs ou opposés" [en función de la estrategia interpretativa, podríamos describir una metáfora como una conflación o como una bifurcación entre las isotopías, según se destacan los rasgos específicos comunes u opuestos] (Rastier, 1998, p. 36). En el mismo artículo, Rastier muestra que, entre las dos tradiciones de nuestra tradición occidental, el realismo empírico, concebido como una representación de lo sensible e ilustrado especialmente por la novela clásica, y el realismo transcendental, asociado con la expresión lírica y con la transmisión verbal de las imágenes interiores, el surrealismo ha elegido una vía antinomista, que destruye las formas clásicas miméticas, tanto las empíricas como las transcendentales y eso sin crear un modo mimético nuevo, "comme si la destruction contenait en elle la construction" [como si la destrucción contuviera en ella misma la creación] (p. 53). En cambio, en el caso de Huidobro, cuya animosidad frente al surrealismo es conocida, se podría más bien hablar de la copresencia a lo largo de su poema de los dos tipos de realismo, empírico y transcendental, lo que explica, entre otras, la posibilidad de conservar un aparente hilo narrativo así como sus extraordinarios recursos de humor. La copresencia de los dos regímenes miméticos rige también la ambivalencia de varios símbolos que conforman la red textual del poema, así como lo mostraremos en la última parte de nuestro artículo.

Evidentemente, Huidobro niega cualquier interés por el realismo y proclama con humor en un manifiesto: "El Arte es una cosa y la Naturaleza otra. Yo amo mucho el Arte y mucho la Naturaleza. Y si aceptáis las representaciones que un hombre hace de la Naturaleza, ello prueba que no amáis ni la Naturaleza ni el Arte" (Huidobro, 1976, p. 734). Con todo eso, cuando nos referimos al realismo empírico en el caso de Huidobro llamamos la atención sobre su concepción abarcadora acerca de la imaginación, 
que incluye también la facultad perceptiva, conforme lo presenta él mismo en su programa:

El poema creacionista se compone de imágenes creadas, de situaciones creadas, de conceptos creados; no escatima ningún elemento de la poesía tradicional, salvo que en él dichos elementos son íntegramente inventados, sin preocuparse en absoluto de la realidad ni de la veracidad anteriores al acto de realización. Así, cuando escribo: "El océano se deshace / Agitado por el viento de los pescadores que silban" "presento una descripción creada" (p. 736).

De hecho, esta concepción sobre la poesía creacionista data de la juventud del poeta, puesto que está ya sintetizada en un verso de "Arte poética" de 1916: "Que todo lo mirado creado sea". El creacionismo de Vicente Huidobro se propuso desde el principio hacer una poesía "universal", perfectamente traducible, puesto que el principal objetivo del poeta consistía en "crear un hecho nuevo", "un objeto creado" que se pudiera representar de la misma forma en todos los idiomas:

Si para los poetas creacionistas lo que importa es presentar un hecho nuevo, la poesía creacionista se hace traducible y universal, pues los hechos nuevos permanecen idénticos en todas las lenguas. Es difícil y hasta imposible traducir una poesía en la que domina la importancia de otros elementos. No podéis traducir la música de las palabras, los ritmos de los versos que varían de una lengua a otra; pero cuando la importancia del poeta reside ante todo en el objeto creado, aquel no pierde en la traducción nada de su valor esencial. [...] La poesía creacionista adquiere proporciones internacionales, pasa a ser la Poesía, y se hace accesible a todos los pueblos y razas, como la pintura, la música o la escultura (Huidobro, 1976, p. 736).

La poesía creacionista se basa en lo que Pound llamaba phanopeia (imagen visual transpuesta en palabras), que se opone a la logopoeia (relacionada con el impacto verbal producido por el lenguaje poético) y a la melopeia (asociada con la musicalidad y el ritmo) (Pérez Villalón, 2010, p. 176). Esta preponderancia de lo visual indica una concepción pictórica sobre el lenguaje, que de hecho, según lo muestra Rastier, es profundamente arraigada en la estética occidental:

Rapportée au problème de la création esthétique, la hiérarchie de la poésie et de la peinture dépend du modèle de la création divine, par modelage ou par profération. [...] Dans la Grèce archaïque, le Logos était 
considéré comme une puissance créatrice, voire théogonique, alors que la philosophie classique laïcise le Logos et s'en tient à une création plastique par modelage ou peinture. [...] Comme nos théories esthétiques nous viennent pour l'essentiel des païens, l'image de la création plastique a prévalu sur celle de la profération [En relación con el problema de la creación estética, la jerarquía de la poesía y de la pintura dependen del modelo de la creación divina, por el modelado o por el proferimiento [... En la Grecia arcaica, el Logos se consideraba una fuerza creadora, o sea teogónica, mientras que la filosofía clásica laiciza el Logos y se atiene a una creación plástica por el modelado o la pintura [...] Como nuestras teorías estéticas provienen esencialmente de los paganos, la imagen de la creación plástica a prevalecido sobre la del proferimiento] (Rastier, 1992b, p. 110).

Esta concepción pictórica sobre el lenguaje se alía pues con una suerte de ingenuo idealismo, que hace del mundo percibido el producto de la imaginación, según los principios de la magia poética, tal como la entendía el poeta en 1916 al proclamar "Que todo lo mirado creado sea". El lenguaje del primer canto, "cargado de contenido, de información, de ideología” (Yurkievich, 1984, p. 84), confiere al discurso un arraigo preciso en una época y un espacio. Las alusiones a la Primera Guerra Mundial y la revolución rusa, el nietzscheanismo ruidoso y los manidos ataques contra el "burgués" pretenden ser, según el programa creacionista, productos de la facultad imaginativa, aunque eso no disminuye la presencia de los elementos relacionados con el mundo empírico en el texto del poema. Así como no se puede decidir si el vuelo de Altazor tiene una orientación centrípeta o centrífuga, el mundo recorrido es a la vez el universo interior y el espacio cósmico y el ojo del poeta se dirige indistintamente hacia adentro y hacia afuera.

En Huidobro, la concepción sobre el lenguaje tiene implicaciones soteriológicas y Altazor se presenta desde el principio como un enfrentamiento dramático con la condición mortal. En la busca del absoluto protagonizada por Altazor, la posibilidad de instituir la novedad a través de una mirada prístina es la principal aliada del optimismo del poeta-mago. No obstante, el optimismo está contrarrestado por dos importantes fuentes de angustia: una deriva de la precariedad del ojo humano, con sus limitaciones espaciales y temporales; la otra está relacionada con la ilusión de las imágenes mentales suscitadas por la poesía, cuyos logros son limitados a pesar de la prepotencia de los poetas. Dicho de otra forma, las dudas de Altazor-mago proceden tanto de la lucidez acerca de la fragilidad del hombre habitante del mundo empírico como de la desconfianza en las conquistas del poeta en calidad de explorador del espacio mental. El principio del canto III se puede 
leer como una autoironía con respecto a la propia poética del creacionismo, que rezaba entre otras "Que todo lo mirado creado sea". Este canto se inicia con una serie de veinte dísticos de rima asonante endecasílabos los primeros ocho y de ritmo variable los demás, cuya estructura semántica remite al tema platónico-cristiano del despojo de las ataduras carnales ("Romped las ligaduras de las venas / Los lazos de la respiración") y la ruptura de los circuitos de representación comunes ("Cadenas de miradas nos atan a la tierra / Romped romped tantas cadenas"). Se estipula la recreación del mundo a través de una nueva mirada ("Porque todo es como es en cada ojo"), según la doctrina del idealismo, en cambio esta recreación puede intuirse como un fenómeno igual de efímero como lo demás ("Dinastía astrológica y efímera / Cayendo de universo en universo") y además se recela de ella porque representa la máxima ilusión de la cual se nutre la poesía. La continuación del canto es un ajusticiamiento de la poesía, vista bien como producto de la imaginación ilimitada (según el programa creacionista mismo, que incluye el mundo empírico percibido en la propia fantasía del poeta), bien como reflejo del mundo interior del poeta (según los patrones del realismo transcendental):

Manicura de la lengua es el poeta

Mas no el mago que apaga y enciende

Palabras estelares y cerezas de adioses vagabundos

Muy lejos de las manos de la tierra

$Y$ todo lo que dice es por él inventado

Cosas que pasan fuera del mundo cotidiano (subr. mío)

Matemos al poeta que nos tiene saturados

La síntesis que concluye el canto, tras la simbólica condena a muerte y entierro de la poesía, consiste en la proclamación de la superioridad de "El simple sport de los vocablos / De la pura palabra y nada más / Sin imagen". A la visión pictórica sobre el lenguaje se le sustituye una visión antirrepresentativa, proclamada como superior ( $y$ de paso superior a las falsas revoluciones poéticas declaradas por otros movimientos de la vanguardia). Con todo eso, ella no aporta ninguna certeza triunfal y está más bien asociada con la condición lúdica, con un mero pasatiempo y ersatz: "Y puesto que debemos vivir y no nos suicidamos / Mientras vivamos juguemos". Al final de este juego se perfila una realidad marcada por el mismo sello de la ambivalencia: "Después nada nada / Rumor aliento de frase sin palabra". La nada puede ser por un lado el vacío lingüístico, tras una suerte de despojamiento total del verbo empleado en su clave ordinaria, y de esta forma encontra- 
mos anticipado aquí el canto VII, pura armonización sonora a-semántica. Por otro lado, la nada también puede ser la nada de la muerte, recorrida por "la risa de los muertos debajo de la tierra" referida en el último verso del canto $\mathrm{V}$.

La imagen mental creada por el poema ha sido denunciada como insatisfactoria en relación con las ansias del poeta-mago que no se contenta con proyectar imágenes, de modo que una lectura del poema que se ataña sólo a los patrones del realismo transcendental es reductiva. Por otra parte, evidentemente, la lectura del poema en la clave del realismo empírico de tipo creacionista (que "crea" lo que "ve" fuera) es también denunciada como insatisfactoria. La ambigüedad de muchas de las metáforas del poema proviene del hecho de que no se puede decidir si ellas nacen de una confluencia o una divergencia de las isotopías.

Ilustraremos este fenómeno con un ejemplo del canto IV. Sobre el fondo de aceleración impuesta por los leitmotiv del Canto IV "No hay tiempo que perder", "Darse prisa darse prisa", la voz poética anuncia en calidad de inminente revelación la visión de lo que está más allá de los límites espaciotemporales:

No hay tiempo que perder

A la hora del cuerpo en el naufragio ambiguo

Yo mido paso a paso el infinito

El mar quiere vencer

Y por lo tanto no hay tiempo que perder

Entonces

Ah entonces

Más allá del último horizonte

Se verá lo que hay que ver

Rastier insiste en sus trabajos en que la significación de una palabra no es fija, sino que es el resultado de un acto hermenéutico que debe considerar el entero texto analizado. Al estudiar las ocurrencias del vocablo "naufragio" en Altazor se puede asentir que él se asocia en el poema huidobriano con la muerte ${ }^{2}$. Por su parte, la muerte se presenta en sus dos aspectos tra-

\footnotetext{
${ }^{2}$ Véanse varias ocurrencias en el canto I: "Cae.../ Cae... / Cae... / Cae al último abismo de silencio / Como el barco que se hunde apagando sus luces"; "Dadme la llave del naufragio". La palabra está muy presente en el canto V: “¿Conoces tú la fuente milagrosa / Que devuelve a la vida los náufragos de antaño?"; "Y caí de naufragio en naufragio de horizonte en horizonte"; El mar se abrirá para dejar salir los primeros náufragos / Que cumplieron su castigo / Después de tantos siglos y más siglos".
} 
dicionales en la cultura occidental: por un lado, amenazadora (de aquí la insistencia en la prisa en todo el Canto IV) y por otro lado, reveladora de los últimos secretos, una vez pasado el límite último. Hacia el final del canto se repite casi invariada la serie de versos citada:

Mis ojos han visto la raíz de los pájaros

El más allá de los nenúfares

Y el ante acá de las mariposas [...]

La eternidad quiere vencer

Y por lo tanto no hay tiempo que perder

Entonces

Ah entonces

Más allá del último horizonte

Se verá lo que hay que ver

La variación del vocablo "mar" por "eternidad" es ilustrativo para el régimen ambivalente que rige los significados. En el primer contexto "mar" remitía al mundo fenoménico que se agolpa sobre el ojo, pidiendo derecho de ciudad e impidiendo una visión clara de lo que está más allá de la percepción natural ("El sondaje es difícil a causa de las olas / Los tumultos que pasan / La apretura continua"). En el segundo contexto, la eternidad se declara potencialmente igual de peligrosa, porque impide ver lo que está de este lado de las percepciones naturales. Es sugestivo que en el primer enunciado, tras la serie de versos sigue un espacio blanco y luego una letanía de imágenes que giran alrededor del ojo, que es uno de los ejes temáticos del poema ("Por eso hay que cuidar el ojo precioso regalo del cerebro"). En cambio, en el segundo enunciado, sin pausa, aparece un vocablo de ocurrencia muy reducida en el poema y casi desprovisto de metaforicidad, que remite al mundo de las experiencias más corrientes: "La ciudad / Debajo de las luces y las ropas colgadas".

El mundo celeste que seduce y el mundo terrestre que reclama crean dos isotopías que se contraponen continuamente, procurando sucesivamente "vencer". La victoria de una sería la aniquilación de la otra y los regímenes miméticos que los rigen se volverían unívocos. La solución del poeta no es ni mantener una continua tensión entre las dos isotopías, como los surrealistas, ni alternar continuamente entre ellas, sino la de imaginar una palabra que no se reduzca a una imagen mental y tampoco salga por completo de los límites de la representación. El final del Canto IV revelará esta palabra y proclamará el triunfo. Se trata del palíndromo "eterfinifrete" que instituye 
un circuito continuo entre la finitud y la eternidad, conservando así la ambivalencia de los símbolos y, con ella, manteniendo en jaque la angustia de la locura y el humor más irresistible:

El pájaro tralalí canta en las ramas de mi cerebro

Porque encontró la clave del eterfinifrete

Rotundo como el unipacio y el espaverso

Uiu uiui

Tralalí tralalá

Aia ai ai aaia i i

La impresionante construcción artística, la asombrosa red de metáforas y la originalidad innegable de las imágenes poéticas no pueden contrarrestar el fracaso del desproporcionado propósito "espiritual" de Altazor. La mortalidad no se puede vencer a través de la poesía y en el momento en que la palabra se diluye en la sonoridad pura, en ecolalias y maridajes arbitrarios de sonidos, como ocurre en el Canto VII, se da inevitablemente la pérdida del significado (en este caso, "el absoluto") al que esa palabra remitía. Dicho de otra forma, asistimos en Altazor al naufragio en el caos de la muerte que, precisamente, el "mago" mencionado en el Prefacio procuraba conjurar. No obstante, si renunciamos a esta lectura basada en el paradigma simbólico tradicional, que tiende a aprehender los textos en calidad de "mundos" textuales, podemos plantear problemas importantes y cuestionar las condiciones estructurales propias del texto, que imponen y determinan los varios tipos de impresiones referenciales que están hechas de imágenes mentales. Aceptemos que "le texte impose des contraintes sur la formation des images mentales, notamment par ses structures sémantiques" [el texto impone coacciones sobre la formación de imágenes mentales, precisamente por sus estructuras semánticas] (Rastier, 1992a, 101) y que el estudio de las isotopías que conforman un texto nos puede esclarecer en mayor medida qué tipos de impresiones referenciales impone el texto huidobriano. En el espacio actual no nos propusimos hacer un recuento exhaustivo de los dispositivos de producción de estas impresiones referenciales y sólo nos limitamos a observar la alternancia de los dos tipos de realismo -empírico y transcendental- que Rastier define en función del parangón privilegiado: el mundo físico o el mundo eidético de las representaciones mentales. Creemos que esta alternancia rige la entera construcción del poema y que el esfuerzo del poeta-mago consiste principalmente en mantener en jaque las dicotomías y de crear un universo en que la palabra sea al mismo tiempo 
"palabra de la tribu", con su referencia habitual, y palabra única, surgida gracias a la magia poética. Entre la representabilidad y la no representabilidad, Huidobro no elige, sino prefiere mantener las dos posibilidades que encierra la palabra poética, gracias a la copresencia de los dos regímenes miméticos mencionados.

\section{REFERENCIAS}

Ávila Rubio, M. (2001). Altazor: la experiencia del triunfo. Lima: UNMSM Fondo editorial, en http://sisbib.unmsm.edu.pe/bibVirtual/Libros/literatura/Altaz_Exp_triunf/indice.htm

Aullón de Haro, P. (1988). "La transcendencia de la poesía y el pensamiento poético de Vicente Huidobro", Revista de Occidente, 86-87, 41-58.

Huidobro, V. (1976). Obras completas (ed. Hugo Montes), t. I, Santiago de Chile: Editorial Andrés Bello.

. (1981). Altazor. Temblor del cielo (ed. René de Costa). Madrid: Editorial Cátedra.

Pérez Villalón, F. (2010). "Huidobro/Pound: Translating Modernism". Huidobro's Futurity: Twenty-First Century Approaches. Editors: Luis Correa-Díaz, Scott Weintraub. Hispanic Issues On Line 6, 167-186.

Rastier, F. (1992a). "Réalisme sémantique et réalisme esthétique". Théorie, Littérature, Enseignement, 10, 81-119. . (1992b). "Généalogie d'Aphrodite - Réalisme et représentation artistique". Littérature, 87, 105-123.

. (1998) "Rhétorique et interprétation - ou le miroir et les larmes". Sémantique et rhétorique (ed. Ballabriga, M.). Toulouse: Editions Universitaires du Sud, 33-57.

Robles, M. (1971)."La disputa sobre la paternidad del creacionismo". Thesaurus: Boletín del Instituto Caro y Cuervo, 26(1), 95-103.

Sucre, G. (1985). La máscara y la transparencia. México: Fondo de Cultura Económica.

Yurkievich, S. (1984). Fundadores de la nueva poesía latinoamericana. Barcelona: Ariel. 